\title{
Scaffolding in the Indonesian classroom from theory and practise
}

\author{
J. A. Foley \\ Director of the Language Center \\ Southeast Bangkok College, Bangkok
}

\begin{abstract}
Too often descriptions of language learning have focused primarily on the language components or the structural features. However, there is an increasing recognition that patterns of discourse realised through text rather than a sentence based approach to language description is turning away from discrete form-based aspects of language learning to focus on the effectiveness of how learners get their messages and ideas across to others. This paper will take as an example the process of writing as it is probably the most difficult of the language skills required of our learners. The cultural context is that of the ASEAN classroom in general and how we can go about scaffolding the writing process to help prepare Indonesian students for their potential role in the ASEAN of the future.
\end{abstract}

Keywords: scaffolding, writing, genre, Indonesian classroom, socio-cultural theories, CLT. 


\section{Introduction}

Many EFL/ESL textbooks in the past have been largely influenced by psychological views of language inspite of the claim that they are based on Communicative Language Teaching (CLT). Structural behavorists emphasised inductive learning of individual sentences one at a time. What was considered as 'learned'was in fact form but not the function.

Take the following example from a EFL textbook to illustrate what we mean.

Target Structure: "If were would

Lesson procedure:

1. Teacher draws the following substitution table on the board:

2. Teacher says the following example of the target structure and asks the whole class to repeat it after him:

If I were a rich man, I would buy a big house.

3. Teacher asks individual students to repeat the same example after him, correcting mistakes and making each student say the sentence until he gets it $100 \%$ correct.

4. Teacher repeats the process with the next example: 
If he were the principal, he would give us a holiday.

5. Teacher points out the target structure, giving further examples.

6. Teacher gives the following prompts, and asks the whole class or individuals to substitute them into the target structure, correcting mistakes in the responses and making the students repeat the correct response:

\begin{tabular}{|c||c|}
\hline $\begin{array}{c}\text { a famous movie star } \\
\text { a doctor } \\
\text { an engineer } \\
\text { a millionaire }\end{array}$ & $\begin{array}{c}\text { sign a million autographs } \\
\text { heal the sick for free } \\
\text { turn rice into chocolate } \\
\text { build bridges for the village } \\
\text { give money to the poor }\end{array}$ \\
\hline
\end{tabular}

The focus here is on the form of the if clause in the sentence. But what role does the if clause play? What is its function? The if adverbial clause is, normally, when placed at the begining of a sentence, to foreground emphasis. In speech this would be done by putting the stress on the if clause in the speaker's intonation pattern.

What we have traditionally found in our textbooks can be summarise as follows:

- Modeling of all learning by the teacher

- The mother tongue was not to be used in the classroom, only the target language.

- New language points to be introduced and practiced 'situationally'. 
- Minimizing of vocabulary but taught in context until all common grammatical struc tures had been learned

- Graded grammar structures expanded from simple to more complex forms.

However, one central deficiency in such approaches is that: they do not pay sufficient attention to the social aspects of language and learning. Both language and learning do not merely have psychological dimensions - they are very much social in nature. More socially and that means more culturally oriented explanations of language learning are needed for a complete account of how language learning takes place'.

\section{Socio-cultural theories}

In the early 60s saw the publication in English of the works of the Russian psychologist Lev Vygotsky (1896-1934).

For Vygotsky 'cultural development' plays the following roles:

- Object regulation: the materials and cultural elements used for learning (textbooks, dictionaries and so on)

- $\quad$ Other regulated: teachers, parents, other students and the social environment

- Self regulation: to achieve a degree of mastery or control of whatever we are doing and most importantly language as a tool for thinking.

In this context Vygotsky saw Scaffolding as essential to attain Self-regulation.

Good teaching is about guidance through providing supporting 'structures' to help the students move from one stage of development to the next. For example, the process of scaffolding in terms of language teaching would provide structured outlines and lists of possible grammatical structures or vocabulary for students' first attempts at writing. How much scaffolding is needed will depend on the level of the students and the nature of the task. 
Within this theory, the concept of object-regulation stresses the importance of providing model texts so that the student starts learning how language is used to achieve a purpose. On the other hand, co-operative learning that is pair-work and group-work, for Vygotsky, was more about opportunities for the more able peer to help the less able. Consequently, tasks and activities should aim to provide for peer guidance in the use of language, rather than just provide for some form of simple oral practise in the language.

\section{The Indonesian classroom}

The emphasis in many Indonesian schools and indeed in many classrooms in the region tends to be on mechanical tasks, such as form based grammar drills, memorizing vocabulary and testing. For example, in too many writing programs, the typically writing assignment is a first and final draft, written in class. Students often receive instruction about writing only after the writing tasks have been completed, meaning that writing is more often assessed than taught. Teachers' feedback on student writing tends to focus on correction of errors at the sentence level or generalized comments.

The following are examples of first tertiary level students' writing in the first week and the last week of their course (duration 14 weeks) where there was limited intervention in terms of the structure of the text or'scaffolding provided in the course. 


\section{Sample of Visuals}

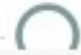

Picture 1 (Week One)

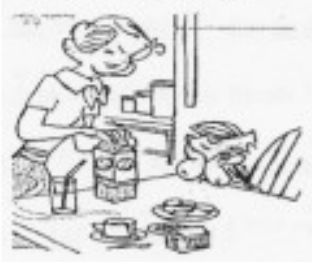

Picture 7 (Week Fourteen)

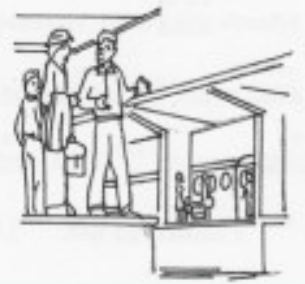




\section{Student G}

Analytical from Writing 1(week 1):

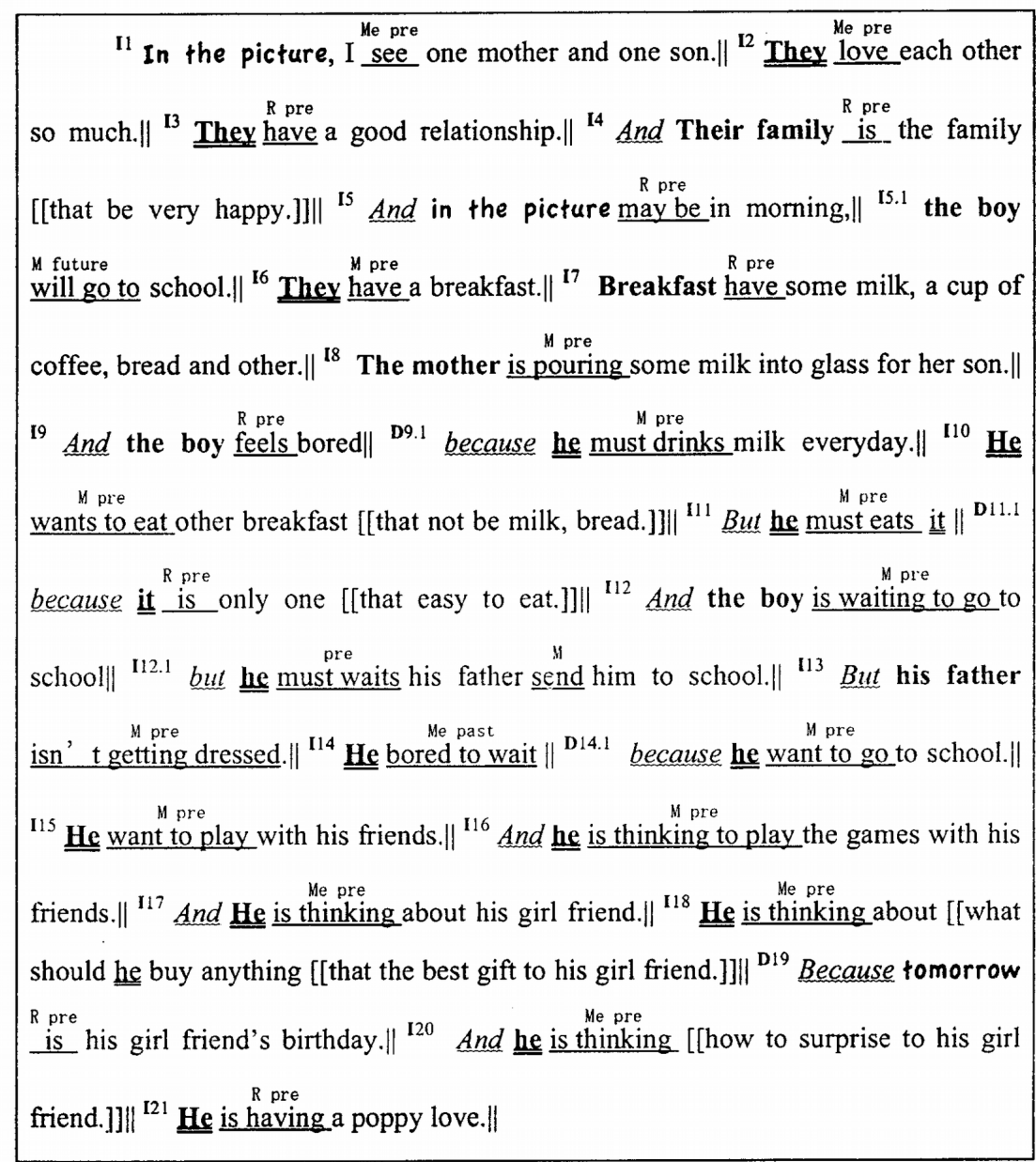




\section{Lexical String 1:}

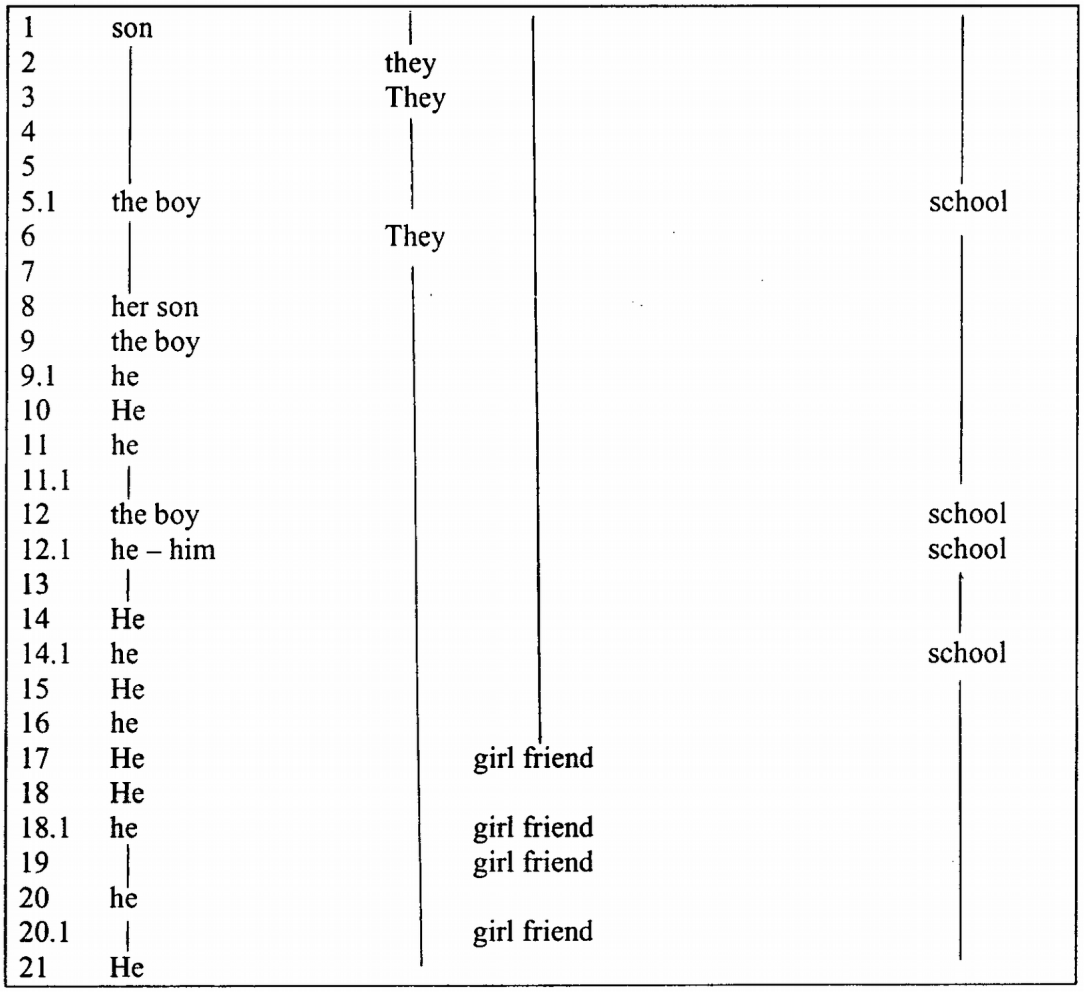

There are several areas that could be discussed with this student but probably the most important is the use of the nominal group (NG). This is the grammatical unit which would allow the widest range of descriptive meanings to be expressed (Foley 2011). There are three possible parts to the structure of the NG: Premodifier, Head and Postmodifier. The ability to construct a complex NG is considered an indicator of developing control in a language. EFL learners tend to employ short NGs depending on how much control they have of the target language. In some languages, the NG is constructed differently as found in Thai where there is no pre-modification kao + pat + sorng + jarn (fried + rice + two + plates $)$.

In this example quoted above 
The majority of the NGs in theme position are pronouns (They, He) or single nouns (Breakfast).

D+H (Their family, the boy) are less frequent

- In complement position $\mathrm{H}+$ post-m [relative clause] is used but often the structure is incorrect: (that be very happy*, that not be milk, bread*, that easy to eat*, that the best gift to his girl friend*).

क The text structure is a description with little structure, very repetitive and few extended nominal groups showing limited control over the target language.

\section{Analytical from Writing 7 (week 14):}

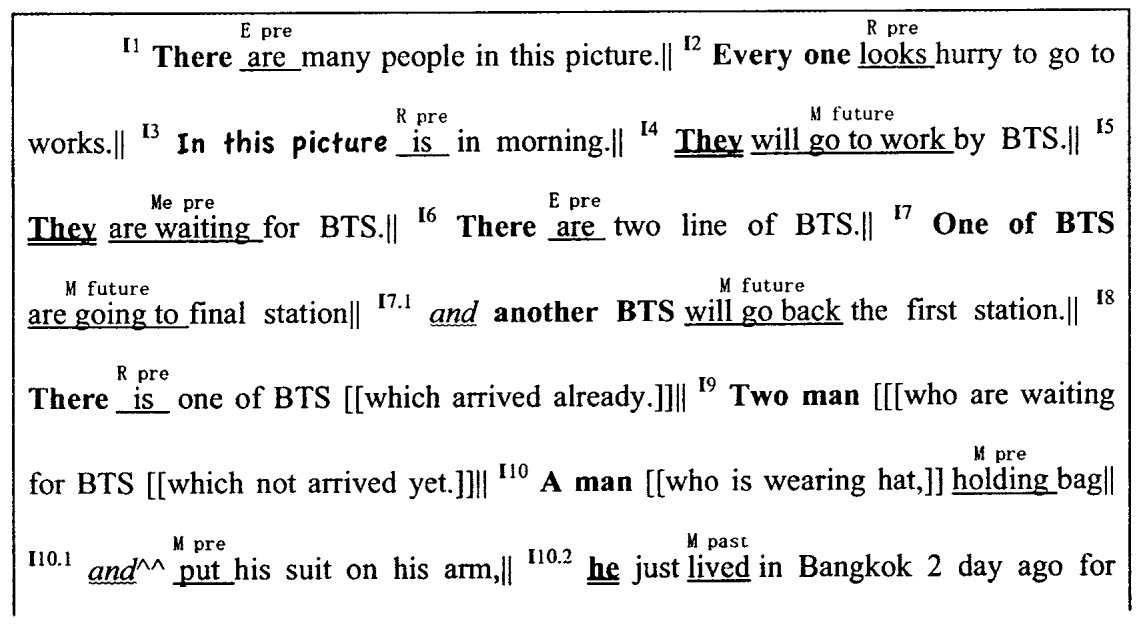




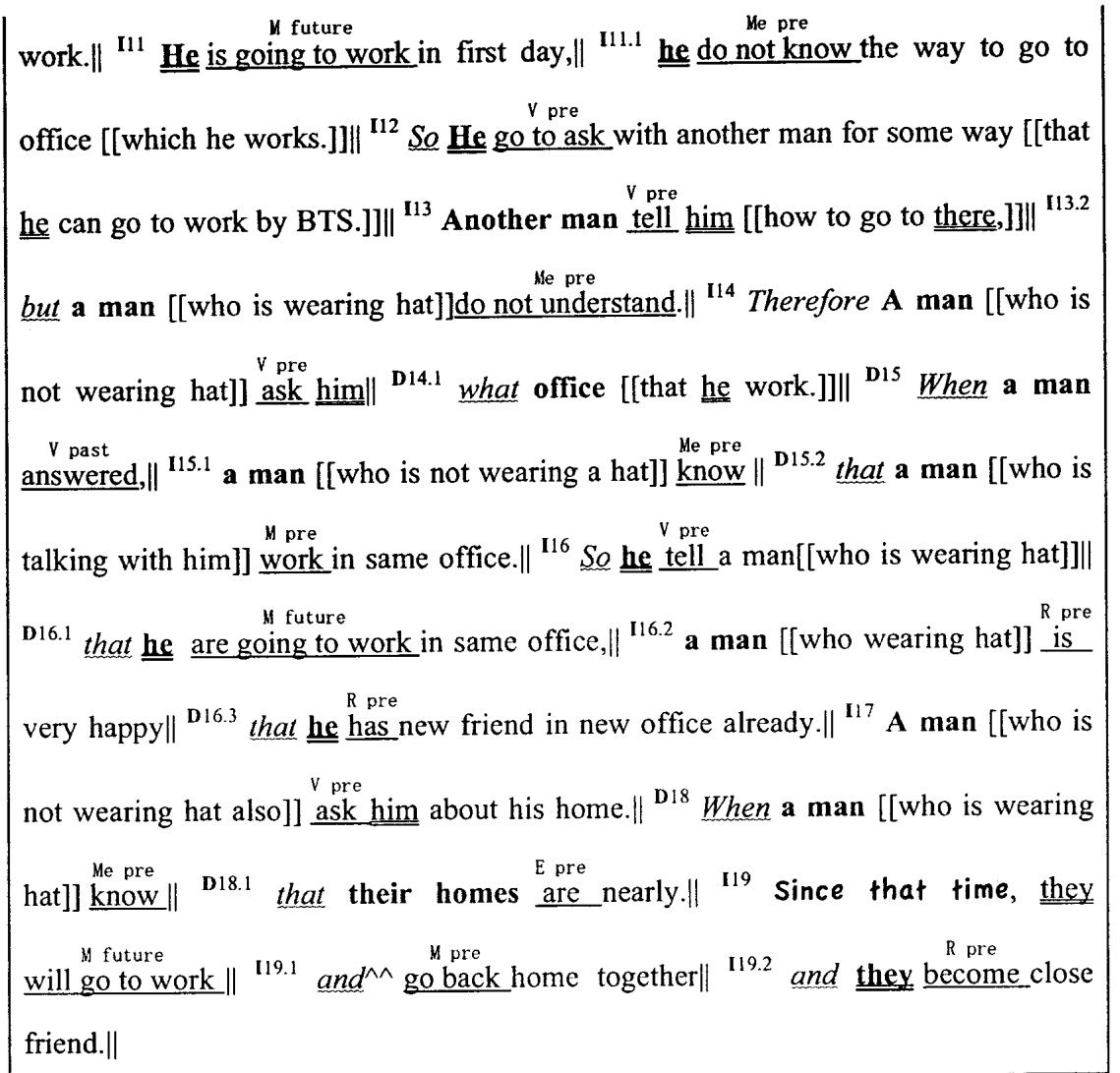




\section{Lexical String 7:}

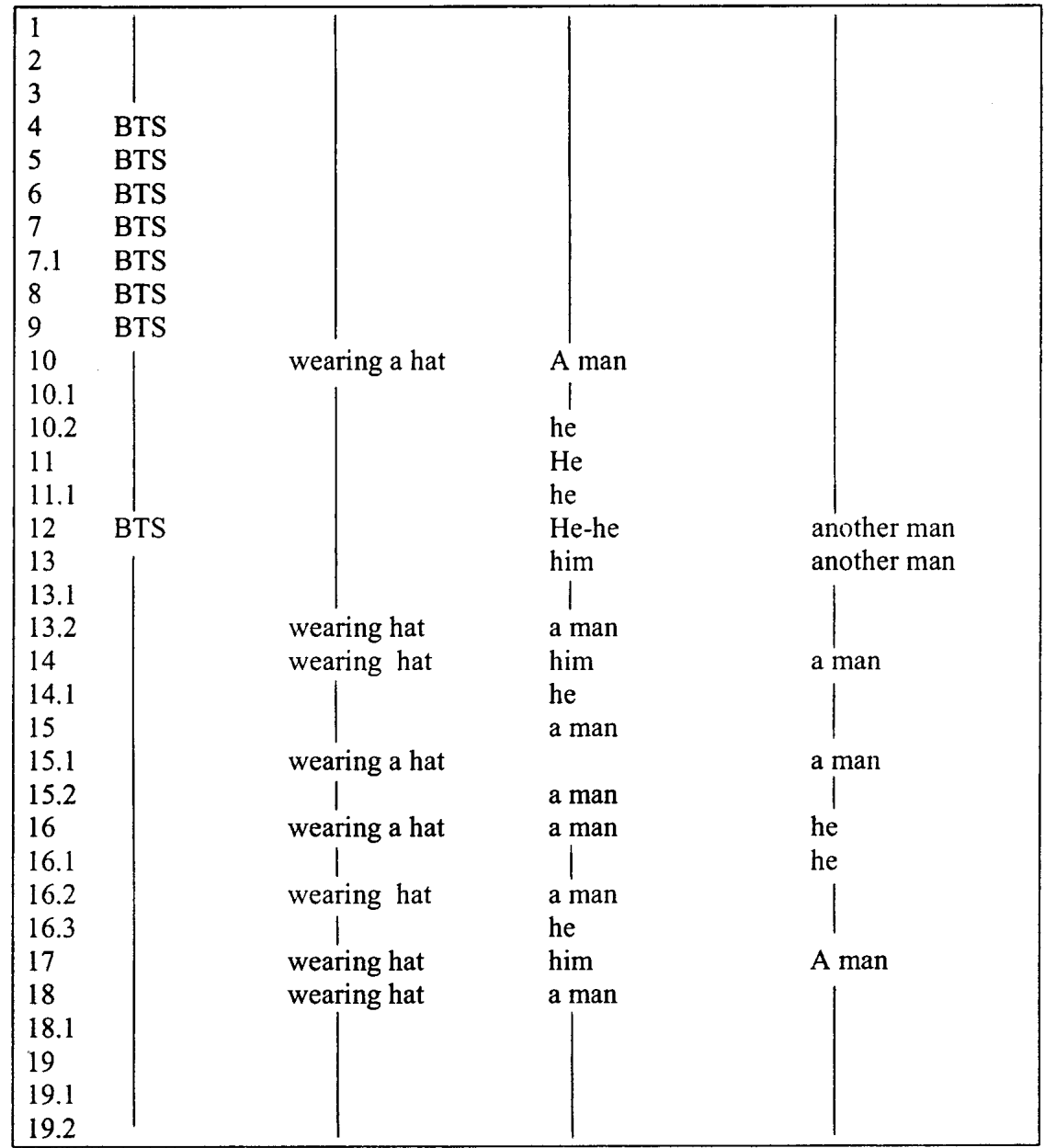

Again, the majority of NGs are pronouns (There, They) or single nouns $\mathrm{H}$ or $\mathrm{D}+\mathrm{H}$ (another BTS, Another man) or $\mathrm{N}+\mathrm{H}$ (One of BTS).

- $\mathrm{D}+\mathrm{H}+$ post-m (relative clause) is used extensively:

A man who is wearing a hat

A man who is not wearing a hat

A man who is talking with him

\% The text structure is a description with little structure, very repetitive and again limited use of extended nominal groups. The use of the relative clause as embedded post modifier simply increases the repetitive effect. 
What makes this writing unsatisfactory is principally because of the repetitive nature of the writing and the student's inability to develop the use of the descriptive power of the NG.

Theme

Theme is the starting point in English of what the speaker or writer is on about.

Speakers/writers use the first element of the clause to indicate the topic and is the way a text

develops cohesion. There are three main types of Theme

Topical theme (TT) [often the subject]

Hamlet is considered Shakespeare's greatest play

Marked Topical theme (MTT) [adverbial]

For 30 years, Shakespeare worked in the theatre

\section{Textual (T)}

However, he moved to London later

\section{The students development by Theme}

In the picture (MTT)

They (TT)

They (TT)

Their family (TT)

The (TT)

The boy (TT)

They (TT)

They (TT)

Breakfast (TT)

The Mother (TT)

The boy. (TT)

He (TT)

He (TT) 
He (TT)

He (TT)

He (TT)

Because (T)

It (TT)

The boy (TT)

He(TT)

He (TT)

He (TT)

He (TT)

His father (TT)

The overall use of either the simple pronoun or a single modified and Head is characterisrtic of immature writing

\section{Scaffolding}

Language is scaffolded through guidance and interaction in the context of shared experience.

The teacher inducts learners into the linguistic demands of these genres that are important to participation in the school and wider community. Gradually responsibility is shifted to the learners as they gain control of the genre. However, before developing a genre- based programme, the teacher or institution will need to conduct an analysis of the teaching/learning context. At its broadest level, this should take in account the culture, history and tradition of the educational setting, English proficiency, learner expectations and assessment requirements. 
To illustrate both the textual and common language features the following are examples of modeling as part of the scaffolding process (Derwianka, 1996).

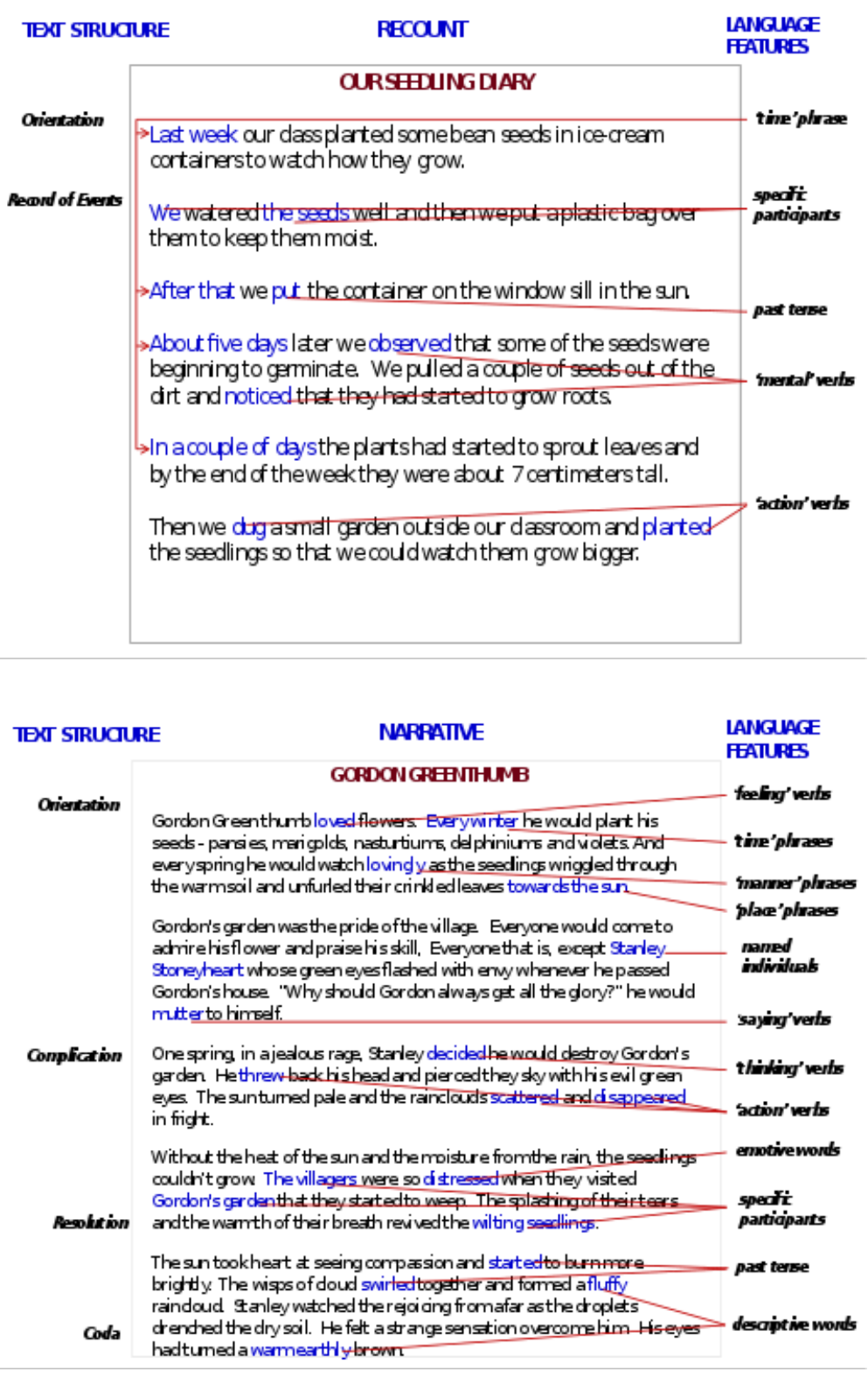




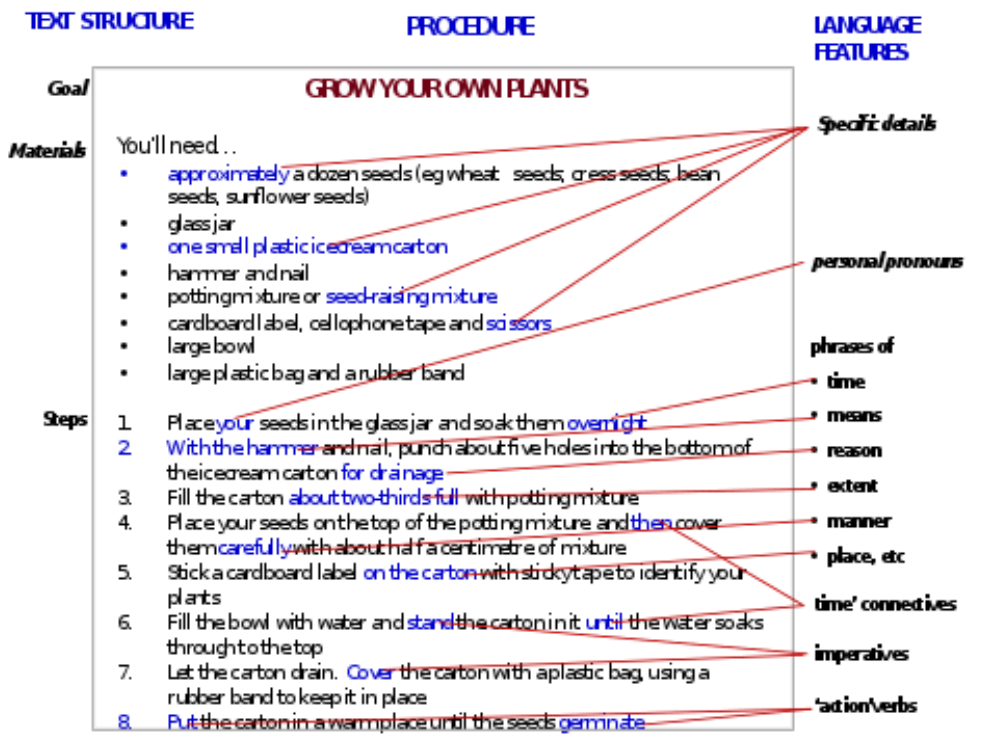

\section{The Volvo Dimension [ad created by the Volvo team to sell the new S90}

People see in Volvo cars lots of different things

Some see power and performance

Others strength

Still others advance technology

Each one of them is right

But, in fact, it is all these elements put together that make a Volvo

The $\mathbf{S} 90$ engine illustrates just what we mean

It's not only powerful

It consumes power with precision and economy.

The $\mathbf{S} 90$ has been hailed as a breakthrough in automotive technology. 
The computerized v-6 engine includes among its many notable features the highly sophisticated ECCS or Electronic Concentrated Control System, which controls airfuel mix, fuel injection, ignition timing and other vital functions with extraordinary accuracy.

In short, the innovative design of the S90 doesn't come from a mere desire to impress you with power. It's an innovation that literally brings you the best of everything.

And it succeeds because it has the intangible yet very real quality that makes Volvo what it is. The Volvo Dimension

\section{The scaffolding cycle}

In scaffolding the teaching/learning cycle is a process that would be expected to cover several classroom sessions. This is especially true in an EFL/ESL situation where language problems would be an additional focus. The starting point is always Preparing the Context and the following explanation of each stage is described below (Shape and Thompson, 1998). 


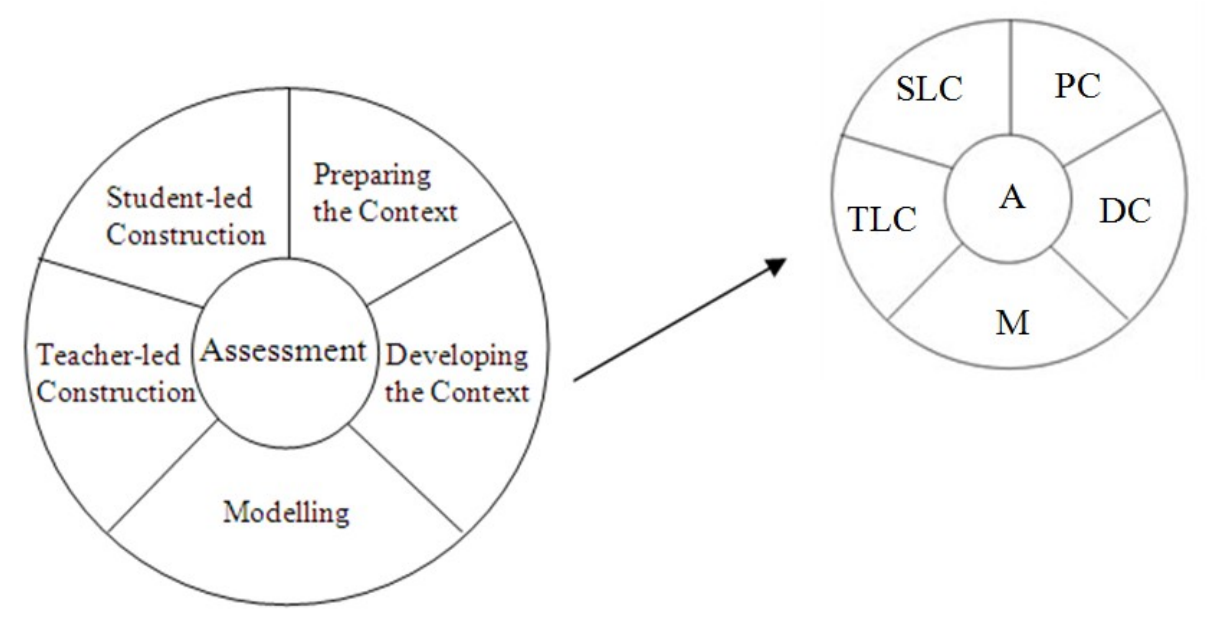

\section{PREPARING THE CONTEXT}

In preparing the context of a unit of work teachers need to ask themselves the

following questions:

2E What is this topic about?

르 What do students already know about this topic?

르 what concepts and language should be focused on to allow students to

comprehend the topic?

The second and third questions are important because students bring both their formal school knowledge (however limited) and their everyday knowledge to the topic

\section{DEVELOPING THE CONTEXT}


In developing the context, the teachers builds up knowledge of the topic (the field) through other related reading materials. This moves the students from an everyday understanding to a specialized understanding of the topic.

This part of the scaffolding will vary according to the amount of information students need. For example, students could research information from the library or watch video as part of information gathering During this phase, students may have to engage with a lot of written language because of the level of technicality and abstraction with which some information is presented when it is written down. Consequently, students will need to be supported as they try to unpack the content.

They will need to explore the ideas orally and build up their understanding through talking about the information and issues presented.

Once students have actively engaged with the content through talking about it, they will need support to express what they have learnt in written language.

\section{MODELING}

In this stage in scaffolding the teacher provides model/models of text that approximate what will be required of students. For example, the text using recount or procedure illustrated above.

\section{TEACHER-LED CONSTRUCTION}

At this stage the teacher and the students jointly construct a piece of writing similar to the model previously discussed. The support of the teacher at this stage is critical in reinforcing linguistic features of the text by referring to the language activities as identified in the model. 


\title{
STUDENT-LED CONSTRUCTION
}

Here the students independently construct texts of their own similar to the model. It is important that the teacher asks the students to write in the same genre and not ask them to write in a different way.

What often happens in classrooms is that teachers and students spend a considerable amount of time building up the field knowledge of the topic by engaging in a range of activities and looking at a variety of different texts. This culminates in an assignment or task which is a written text of some kind. While students are working on their text they could be conferencing with other students or the teacher for guidance on both the content and language to be used in their writing.

\begin{abstract}
ASSESSMENT
Assessment lies in the center of the model, with the teacher monitoring the ongoing progress of students at all stages. The teacher determines student understanding of both the content and language demands of the unit of work and focuses on areas of need or passes quickly through areas with which students are already familiar.
\end{abstract}

\section{Pedagogical issues: scaffolding in the classroom.}

As can be seen from the example of scaffolding illustrated here, all the major language skills of listening, speaking reading and writing are involved at the same time.

There is a danger, however, that scaffolding such genres may mean that they are taught as 'items' in a textbook. Rather, we should be asking our students: what is my purpose in 
writing/ who are my audience? Students are often simply taught the name and stages of the genre. But by focusing first on the social purpose, students would then be able to understand why the text unfolds in this way, instead of simply following a recipe. Contemporary notions of genre emphasize the flexibility and rhetorical nature of genres rather than formulaic and static rules or conventions.

Teachers need to be aware of and explicitly teach the strategies they expect students to use in the classroom and in real life. This means helping students develop skills for questioning and discussion that enables them to develop the language capacities that display their knowledge. Scaffolding can help learners gain access to educational discourses (the sciences, economics and so on) that they may not otherwise be familiar in their daily lives. At the same time, this can provide them with conceptual tools for reflecting on language as they engage in activities that help them develop their new knowledge.

\section{References}

Derewianka, B. 1996. Exploring the Writing of Genres. Nottingham: The United Kingdom Reading Association (UKRA)

Foley, J.A. 2011. Grammar, Meaning and Discourse. Bangkok: Assumption University Press.

Foley, J.A. 2012. Unscrambling the Omelette: Second Language Acquisition: Social and Psychological Dimensions. Bangkok: Assumption University Press.

Johnson, K. and Johnson, H. 1998. Communicative methodology. In K. Johnson, and H. Johnson (eds.), Encyclopedic Dictionary of Applied linguistics. Oxford: Blackwell.

Sharpe, T. and Thompson, J. 1998. Accessing Learning. Sydney: NSW Catholic Education Office. 